\title{
Enhancing the effectiveness of an assertive outreach team: case study
}

\author{
Abrar Hussain, ${ }^{1}$ Tanya Thirkell, ${ }^{1}$ Azaad Taher $^{1}$
}

The Psychiatrist (2011), 35, 266-268, doi: 10.1192/pb.bp.110.031963

${ }^{1}$ Central and North West London NHS Foundation Trust

Correspondence to Abrar Hussain (abrarhussain@nhs.net)

First received 19 Jul 2010, final revision 12 Jan 2011, accepted 3 Feb 2011
Aims and method To evaluate the effectiveness of the Harrow Assertive Outreach Team in reducing hospital admissions. We compared first- and second-year admissions of a cohort of 76 patients.

Results Significant reductions in the number of admissions and number of days admitted were noted in the second year. In the subcohort of patients admitted in both years, the reduction in the number of admissions was significant but reduction in number of days admitted was not.

Clinical implications Hospital admissions may be reduced by appointment of consultant psychiatrist and approved mental health practitioner, home treatment approach and intensive case management.

Declaration of interest All authors are members of the Harrow Assertive Outreach Team.
The National Service Framework for Mental Health introduced assertive community treatment (assertive outreach) teams in 1999 as part of provision of comprehensive services for the promotion and treatment of mental health. ${ }^{1}$ A Cochrane review in 1998 concluded that assertive community treatment was a clinically effective approach to managing the care of people with a severe mental illness in the community. ${ }^{2}$

Over the years, researchers have debated the effectiveness of this model as evidence for clinical efficacy varied in different countries. A randomised controlled trial (REACT) involving 251 service users in London failed to show significant differences between assertive community treatment and usual care in in-patient bed use and clinical or social outcomes, but participants found assertive community treatment more acceptable and engaged better with it. ${ }^{3}$ These findings, published in 2006 , were at 18 months after randomisation. Results at 3 years after randomisation were similar, thereby questioning the continuing investment in assertive community treatment. ${ }^{4}$ However, there is evidence that assertive outreach teams are able to maintain engagement with service users and that this model is popular with both staff and service users. ${ }^{5}$

\section{Setting}

The Harrow Assertive Outreach Team was established in 1999. It comprised a manager, community psychiatric nurses, social workers and occupational therapists. A consultant psychiatrist was appointed to the team in September 2007 and in April 2009 a specialty registrar was appointed. The team has high fidelity to the assertive community treatment model and is compliant with the Department of Health Mental Health Policy Implementation Guide. ${ }^{6}$ The team supports service users considered to be at high risk of disengaging from services. They follow an individualised needs-led approach to help users develop skills and independence. The team aims to promote treatment adherence in the community thereby focusing on reducing in-patient admission. Apart from normal working hours from Monday to Friday (09:00 to 17:00), the team operates an on-call system out of hours including weekends.

In the first year of the study, the team had four community psychiatric nurses, one approved social worker, two occupational therapists, two support workers, onetenth whole-time equivalent psychologist and a team leader, making the service user: care coordinator ratio ten:one. The team consultant did not provide in-patient care if any of the patients needed admission.

\section{Aim}

The aim of the study was to evaluate the effectiveness of the Harrow Assertive Outreach Team in reducing hospital admissions to the psychiatric in-patient unit in a cohort of patients followed for 2 years.

\section{Method}

The successive 12-month periods used for the study were 1 March 2007 to 1 March 2008 and 1 March 2008 to 1 March 2009. The study looked at comparing the number of individual patients admitted, number of total admissions and number of days of hospital admission. We used a cohort 
of 76 patients who were on the assertive outreach team case-load on 1 March 2007. New patients who were accepted by the assertive outreach team after this date were not included so as to maintain consistency of the sample. Data were collected from an assertive outreach team register which had entries of all admissions and discharges. The entries were also confirmed using Jade, the electronic patient database (www.jade.co.nz/health/mental.htm).

\section{Results}

A majority of the patients in the cohort (77.6\%) had an ICD10 diagnosis of schizophrenia ${ }^{7}$ as noted from their case files and electronic records, and most lived independently $(85.6 \%)$. In terms of medication, $42 \%$ of the patients were on depot antipsychotic medication and $52.6 \%$ had no substance misuse. In a broad sense, therefore, our cohort represented service users with a functional mental illness living independently, with approximately half of them using drugs or alcohol. There was limited day care and specialist accommodation and no access to services like befriending.

During the first 12 months of the study, 26 service users were admitted to the in-patient unit. This involved a total of 38 admissions. In contrast, only 16 service users were admitted in the second year, involving just 18 admissions (Table 1). Statistical analysis using the paired exact test revealed a weak evidence of a reduction in the occurrence of service users being admitted during the second 12 months $(P=0.08)$ (Table 2). The Wilcoxon matched-pairs test was used to detect a statistically significant difference in the number of admissions. A significant reduction was seen in the number of admissions $(P=0.007)$.

In terms of the total number of days spent in hospital, a reduction was seen from 4064 days during the first 12 months to 2250 days in the second year. This is a $44.64 \%$ reduction in the number of days of hospital bed use. Statistical analysis using the Wilcoxon matched-pairs test showed a significant difference in the number of days admitted $(P=0.04)$.

There were 8 service users who were admitted to hospital both in the first and the second year (Table 3). Analysis of this subset revealed that between them, the 8 service users had had 14 admissions in the first year. This dropped to 8 admissions in the following year as all service users had one admission each. This is a $42.86 \%$ reduction in the number of admissions. The total number of days spent in hospital also saw a decrease from 1195 to 951 , a $20.42 \%$ reduction. Only three service users spent more days in hospital during the second time period.

Statistical analysis using Wilcoxon matched-pairs test indicated a significant reduction in the number of admissions for this patient group for the second 12-month period $(P=0.03)$. Although there was a trend towards a reduction in the number of days admitted, this result was not statistically significant (Table 4).

\section{Discussion}

This is the first service evaluation in the Harrow Assertive Outreach Team looking at hospital admission. There was a clear reduction in hospital admission in the cohort of
Table 1 Comparison of number of patients, number of admissions and number of days spent in hospital

\begin{tabular}{lccc} 
Parameter & $\begin{array}{c}\text { March 2007- } \\
\text { March 2008, } n\end{array}$ & $\begin{array}{c}\text { March 2008- } \\
\text { March 2009, } n\end{array}$ & $\begin{array}{c}\text { Reduction } \\
\%\end{array}$ \\
\hline Patients & 26 & 16 & 38.46 \\
\hline Admissions & 38 & 18 & 52.63 \\
\hline Days & 4064 & 2250 & 44.64 \\
\hline
\end{tabular}

Table 2 Statistical analysis of the parameters

\begin{tabular}{lccc} 
Outcome & $\begin{array}{c}\text { First 12 } \\
\text { months }\end{array}$ & $\begin{array}{c}\text { Second 12 } \\
\text { months }\end{array}$ & $P$ \\
\hline Any admission, $n(\%)$ & $26(34)$ & $16(21)$ & 0.08 \\
\hline $\begin{array}{l}\text { Outcome per patient, } \\
\text { mean (s.d.) }\end{array}$ & & & \\
$\quad$ Admissions & $0.50(0.79)$ & $0.24(0.49)$ & 0.007 \\
Days admitted & $53.5(103.7)$ & $29.6(69.5)$ & 0.04 \\
\hline
\end{tabular}

Table 3 Readmission pattern of patients

\begin{tabular}{|c|c|c|c|c|}
\hline \multirow[b]{2}{*}{$\begin{array}{l}\text { Patient } \\
\text { number }\end{array}$} & \multicolumn{2}{|c|}{ Admissions, $n$} & \multicolumn{2}{|c|}{ Days admitted, $n$} \\
\hline & $\begin{array}{c}\text { March } \\
\text { 2007- } \\
\text { March 2008 }\end{array}$ & $\begin{array}{c}\text { March } \\
2008- \\
\text { March 2009 }\end{array}$ & $\begin{array}{c}\text { March } \\
\text { 2007- } \\
\text { March 2008 }\end{array}$ & $\begin{array}{c}\text { March } \\
2008- \\
\text { March 2009 }\end{array}$ \\
\hline 1 & 3 & 1 & 209 & 90 \\
\hline 2 & 2 & 1 & 197 & 77 \\
\hline 3 & 2 & 1 & 89 & 101 \\
\hline 4 & 2 & 1 & 140 & 52 \\
\hline 5 & 1 & 1 & 44 & 34 \\
\hline 6 & 2 & 1 & 330 & 202 \\
\hline 7 & 1 & 1 & 117 & 289 \\
\hline 8 & 1 & 1 & 69 & 106 \\
\hline Total & 14 & 8 & 1195 & 951 \\
\hline
\end{tabular}

Table 4 Statistical analysis of readmission rates

\begin{tabular}{lccc} 
& \multicolumn{2}{c}{ Mean (s.d.) } & \\
\cline { 2 - 3 } Outcome per patient & $\begin{array}{c}\text { First 12 } \\
\text { months }\end{array}$ & $\begin{array}{c}\text { Second 12 } \\
\text { months }\end{array}$ & $P$ \\
\hline Admissions, $n$ & $1.75(0.71)$ & $1.00(0.00)$ & 0.03 \\
\hline Days admitted, $n$ & $149.4(93.2)$ & $118.9(85.0)$ & 0.48 \\
\hline
\end{tabular}

patients in the second time period. We present the possible reasons for this result.

\section{Appointment of a consultant psychiatrist}

The team benefited from the role of a part-time consultant psychiatrist who was appointed in September 2007. This could have played a major role in reducing the admissions to hospital in the second year. The consultant provided 
medical input in the form of attending team meetings, conducting patient reviews and writing prescriptions. The consultant's presence also helped to formulate complex cases, assess mental states and risks, and design a plan of action. Prior to this, team members had to consult with the sector consultants regarding arranging urgent reviews and organising prescriptions. This was cumbersome and time consuming. It also meant difficulty in initiating an immediate response to an individual whose mental health was deteriorating.

\section{Appointment of an approved mental health practitioner}

In December 2007, the team appointed an approved mental health practitioner (AMHP). The team had been without a social worker for 2 years at this point. The appointment of the AMHP was in line with suggestions put forth by the Department of Health, according to which strong links to Social Services and the ability to undertake thorough assessments and activate services as needed was required. This also enhanced the skill mix for the team as recommended by a Department of Health report focusing on assertive outreach in mental health in England. ${ }^{8}$

\section{Improvement in the home treatment approach}

Owing to the above, the team was in a position to adopt the home treatment approach more rigorously. This involved carrying out daily visits and supervising medication if needed. Signs of relapse were detected early, treatment options were discussed and appropriate interventions were implemented without unnecessary delays. Flexible working times of staff meant that individuals could be seen outside the usual working hours. It is also important to mention that our team was supported occasionally by the local crisis resolution team to manage multiple visits to a patient in a day. Although we do not have data in this respect, discussions with the crisis resolution team have revealed that their input was minimal.

\section{Intensive case management}

An improvement in intensive case management was noted in the team. Although the team used this approach in the past, it was more effective in adopting it due to a change in leadership. We feel this had a significant contribution to the results noted in this study. Although the UK700 trial $^{9}$ in 2002 showed that intensive case management failed to reduce hospital admission, a qualitative investigation of the trial in 2003 suggested that intensive case management was better able than standard case management to reduce admission by enabling proactive casework involving action that was sensitive to individual circumstances and that anticipated crises.

\section{Limitations}

Although it is interesting to note a huge reduction in the use of in-patient services between the two time periods, we acknowledge that our study has limitations due to its design as a service evaluation. We have not compared two models of care in our study and hence are unable to draw comparative inferences. A before/after design brings inherent limitations to the study.

We are unable to arrive at the exact reasons for the drop in admission rates and at best can only propose the possible reasons that have been observed between the two time periods. It is possible that an increased number of contacts could have an impact on the results. It is important to highlight that service users had contact with individual sector consultants before the team consultant joined the team. An increase in contacts would be mainly with the AMHP, and overall we feel that this alone may not have made a significant impact on the results observed.

We acknowledge that it will not be possible to keep reproducing the trend seen in this study. By continuing to adhere to the assertive community treatment model, the team may be able to demonstrate a reduction in hospital admissions in the future. However, at some point we are bound to reach the saturation level after which further reduction in admissions will not be practically possible. This has been recognised as a negative influence of intensive case management. ${ }^{10}$

\section{About the authors}

Abrar Hussain, specialty registrar, Tanya Thirkell, consultant psychiatrist, Azaad Taher, team manager, Harrow Assertive Outreach Team, Central and North West London NHS Foundation Trust, Harrow, Middlesex, London.

\section{References}

1 Department of Health. National Service Framework for Mental Health: Modern Standards and Service Models. Department of Health, 1999.

2 Marshall M, Lockwood A. Assertive community treatment for people with severe mental disorders. Cochrane Dat Syst Rev 1998; 2: CD001089.

3 Killaspy $\mathrm{H}$, Bebbington $\mathrm{P}$, Blizard R, Johnson S, Nolan F, Pilling S, et al. The REACT study: randomised evaluation of assertive community treatment in north London. BMJ 2006: 332: 815-20.

4 Killaspy H, Kingett S, Bebbington P, Blizard R, Johnson S, Nolan F, et al. Randomised evaluation of assertive community treatment: 3-year outcomes. Br J Psychiatry 2009; 195: 81-2.

5 Killaspy $\mathrm{H}$. Assertive community treatment in psychiatry. BMJ 2007; 335: 311-2.

6 Department of Health. Mental Health Policy Implementation Guide. Department of Health, 2001

7 World Health Organization. The ICD-10 Classification of Mental and Behavioural Disorders. WHO, 1993.

8 Department of Health. Assertive Outreach in Mental Health in England: Report from a Day Seminar on Research, Policy and Practice. Department of Health, 2005

9 Weaver T, Tyrer P, Ritchie J, Renton A. Assessing the value of assertive outreach. Qualitative study of process and outcome generation in the UK700 trial. Br J Psychiatry 2003; 183: 437-45.

10 Tyrer P. Are small case-loads beautiful in severe mental illness? $\mathrm{Br} J$ Psychiatry 2000; 177: 386-7. 